\title{
Transfer hospitalizations for pediatric severe sepsis or septic shock: resource use and outcomes
}

\author{
Folafoluwa O. Odetola ${ }^{1,2^{*}}$ and Achamyeleh Gebremariam²
}

\begin{abstract}
Background: Sepsis is a major cause of child mortality and morbidity. To enhance outcomes, children with severe sepsis or septic shock often require escalated care for organ support, sometimes necessitating interhospital transfer. The association between transfer admission for the care of pediatric severe sepsis or septic shock and in-hospital patient survival and resource use is poorly understood.

Methods: Retrospective study of children 0-20 years old hospitalized for severe sepsis or septic shock, using the 2012 Kids' Inpatient Database. After descriptive and bivariate analysis, multivariate regression methods assessed the independent relationship between transfer status and outcomes of in-hospital mortality, duration of hospitalization, and hospital charges, after adjustment for potential confounders including illness severity.

Results: Of an estimated 11,922 hospitalizations (with transfer information) for pediatric severe sepsis and septic shock nationally in 2012, 25\% were transferred, most often to urban teaching hospitals. Compared to nontransferred children, transferred children were younger, and had a higher frequency of extreme illness severity ( $84 \%$ vs. $75 \%, p<.01$ ), and of multiple organ dysfunction ( $32 \%$ vs. $24 \%, p<.01$ ). They also had higher use of invasive medical devices including arterial catheters, invasive mechanical ventilation, and central venous catheters; and of specialized technology, including renal replacement therapy ( $6.2 \%$ vs. $4.6 \%, p<.01)$ and extracorporeal membrane oxygenation $(5.7 \%$ vs. $1.8 \%, p<.01)$. Transferred children had longer hospitalization and accrued higher charges than non-transferred children $(p<.01)$. Crude mortality was higher among transferred than non-transferred children ( $21.4 \%$ vs.15.0\%, $\mathrm{p}<.01)$, a difference no longer statistically significant after multivariate adjustment for potential confounders (Odds Ratio:1.04, 95\% Confidence interval: 0.88-1.24). Similarly, adjusted length of hospital stay and hospital charges were not statistically different by transfer status.
\end{abstract}

Conclusion: One in four children with severe sepsis or septic shock required interhospital transfer for specialized care associated with greater use of invasive medical devices and specialized technology. Despite higher crude mortality and resource consumption among transferred children, adjusted mortality and resource use did not differ by transfer status. Further research should identify quality-of-care factors at the receiving hospitals that influence clinical outcomes and resource use.

Keywords: Sepsis, Hospitalized children, Mortality, Teaching hospitals, Length of stay, Hospital charges

\footnotetext{
*Correspondence: fodetola@med.umich.edu

'Department of Pediatrics and Communicable Diseases, Division of Pediatric

Critical Care Medicine, 6C07, 300 North Ingalls Street, Ann Arbor, Ml 48109,

USA

${ }^{2}$ Child Health Evaluation and Research Center, University of Michigan, Ann

Arbor, Ml 48109, USA
}

(c) The Author(s). 2019 Open Access This article is distributed under the terms of the Creative Commons Attribution 4.0 International License (http://creativecommons.org/licenses/by/4.0/), which permits unrestricted use, distribution, and reproduction in any medium, provided you give appropriate credit to the original author(s) and the source, provide a link to the Creative Commons license, and indicate if changes were made. The Creative Commons Public Domain Dedication waiver (http://creativecommons.org/publicdomain/zero/1.0/) applies to the data made available in this article, unless otherwise stated. 


\section{Background}

Sepsis is a major contributor to child mortality and morbidity [1-3], with significant in-hospital cost burden $[1,3]$. The occurrence of organ dysfunction in the septic state, exemplified by severe sepsis or septic shock, is associated with elevated risk of adverse outcomes including death [4]. To ameliorate organ dysfunction, patients with severe sepsis and septic shock often require escalated care to provide artificial organ support such as continuous renal replacement therapy (CRRT) or extracorporeal membrane oxygenation (ECMO). Given the differential capacity of hospitals to provide such specialized resources, deployment of these advanced organsupportive therapeutic modalities often requires transfer to hospitals with such resources $[5,6]$.

Given the time-sensitive nature of care for children with severe sepsis or septic shock, and the detrimental consequences of delayed definitive and resuscitative care, including lower survival and increased morbidity $[7,8]$, it is important to investigate for any association between transfer admission for the care of pediatric severe sepsis or septic shock and in-hospital patient survival and resource use. The research might elucidate opportunities to alleviate illness burden and the associated resource use burden and provide insight to approaches to improve healthcare delivery for children with sepsis.

The study was conducted to test the hypothesis that children with severe sepsis or septic shock who undergo interhospital transfer have higher in-hospital mortality, longer hospitalization, and higher overall hospital charges compared with those not transferred.

Some of the results of this study have been previously reported in the form of an abstract [9].

\section{Methods}

\section{Study design}

We conducted a retrospective study of hospitalized children 0-20 years old, with severe sepsis or septic shock. Our data source was the 2012 Kids' Inpatient Database (KID), Healthcare Cost and Utilization Project (HCUP), developed by the Agency for Healthcare Research and Quality. The KID sample includes approximately 3 million pediatric discharge records obtained from 4179 hospitals in 44 states, drawn from the four major U.S. census regions [10]. The KID is the only national, all-payer database of hospitalizations for children. The database is publicly available and contains $80 \%$ of the normal non-newborn discharges from these states and is nationally representative with the inclusion of discharge weights in analyses. Information on patient demographics, hospital characteristics, and diagnosis/procedure codes is included for each hospitalization [10].

\section{Study sample and variable identification}

International Classification of Diseases, ninth revision, clinical modification (ICD-9-CM) codes were used to identify children with a primary or secondary diagnosis of severe sepsis (995.92) or septic shock (785.52).

Dependent (outcome) variables: In-hospital mortality, hospital length of stay (LOS), and hospital charges. Independent variables:

- The exposure variable for the analysis was the patient transfer status (transfer hospitalizations to the study hospital vs. non- transfer hospitalizations).

- Patient characteristics of study interest were: age (categorized: 0-11 months; and 1-5, 6-10, 11-15, 16-20 years), sex, number of dysfunctional organ systems, presence and count of comorbidities, primary insurance payer (categorized: public, private, and self-pay/other), and severity of illness using the All-patient refined diagnosis related group (APRDRG) classification within the KID [10]. The categories of APRDRG-severity of illness - minor, moderate, major, and extreme - are hereafter referred to as illness severity. The APRDRG severity classification is a proprietary, validated, and extensively used measure of illness severity that utilizes patient discharge data including principal and secondary diagnoses, procedures, and demographic information to assign patients to subclasses of illness severity [10]. Due to small sample size for hospitalizations with minor illness severity, the categories for minor and moderate illness severity were combined for the analyses. Applying methodology previously described in the literature [11], Comorbidities were identified using ICD-9-CM codes, and displayed in Appendix A. Organ dysfunction was similarly identified using ICD-9-CM codes, applying methodology previously described in the literature [12], and displayed in Appendix B.

- Hospital characteristics of study interest were: the type of hospital (categorized: location and teaching status: teaching urban, non-teaching urban, and rural hospital), and the census region [10]. Teaching hospital status was determined by whether a hospital had an American Medical Association-approved residency program, was a member of the Council of Teaching Hospitals, or had a ratio of full-time equivalent interns and residents to beds of .25 or higher [10]. Rural-urban designation of hospitals was determined by the core-based statistical area (CBSA). Hospitals residing in counties with a CBSA type of metropolitan were considered urban, while hospitals with a 
CBSA type of micropolitan or non-core were classified as rural [10]. Due to the rarity of rural teaching hospitals, data from rural hospitals were not specified by teaching status in the KID [10]. Of note, for children who underwent interhospital transfer, the study hospital is the receiving hospital.

- Use of invasive medical technology during hospitalization was determined using ICD-9-CM procedure codes. These included:

I. Invasive medical devices: invasive mechanical ventilation (96.7), arterial catheterization (38.91), tracheostomy (31.1-31.29), central venous catheterization (38.93, 89.62); and,

II. Specialized medical technology: continuous renal replacement therapy/dialysis - CRRT (38.95, V45.11, 39.95), and extracorporeal membrane oxygenation - ECMO (39.65).

III. Cardiopulmonary resuscitation - CPR (99.60). This procedure was included as an invasive procedure given prior report of elevated risk of mortality if CPR occurred around the time of interhospital transfer of children to intensive care settings [13].

The Institutional Review Board of the University of Michigan Medical School approved the study.

\section{Statistical analysis}

The number of hospitalizations for severe sepsis or septic shock was determined after excluding hospitalizations with missing transfer information. Thereafter, patient and hospital characteristics, and the frequency of use of invasive medical technology were compared according to the transfer status of the patients. Additionally, to assess for potential confounding, the outcome variables of in-hospital mortality, hospital LOS, and overall hospital charges were compared among hospital and patient characteristics, invasive medical technology, and patient transfer status. Independent variables associated with the outcome variables with $p$ value $\leq 0.20$ in bivariate analyses, and those that statistically differed by transfer status with $p$ value $\leq 0.20$, were included in multivariate regression models which were fit to assess the independent association between transfer status and the outcome variables. In these analyses, multivariable logistic regression, negative binomial regression and multiple linear regression models for complex survey data were fit to assess the independent association of transfer status with in-hospital mortality, LOS, and hospital charges respectively, after adjustment for potential confounders including illness severity.
The number of hospitalizations in the results was unweighted, while all effect estimates and accompanying $95 \%$ confidence intervals were calculated using sample weights to account for the complex survey design and obtain national estimates. All estimates used the survey commands in Stata for Windows (Stata Corp.; College Station, Texas) version 15, which accounted for the complex survey design. To allow generation of stable estimates, cell frequencies that were too small $(<70)$ for precise estimation were suppressed in the report as recommended by AHRQ [10].

\section{Results}

There were 8533 hospitalizations with severe sepsis or septic shock with transfer information in the database, representing an estimated 11,922 hospitalizations for pediatric severe sepsis or septic shock nationally in 2012 . Of the 8533 hospitalizations, 2151 (25.4\%) were associated with interhospital transfer, most often to urban teaching hospitals (Table 1). In the overall study cohort, extreme illness severity was observed in $77 \%$ of hospitalizations, comorbidities in $75 \%$ of children, and multiple (2 or more organ-system involvement) organ dysfunction in $26.4 \%$. In-hospital mortality was $17 \%$, average length of stay was 22 days, and the average charge per hospitalization was $\$ 314,950$.

In bivariate analysis, patient and hospital characteristics varied by transfer status. In comparison with nontransferred children, transferred children were younger and had higher frequency of extreme illness severity ( $84 \%$ vs. $75 \%, p<.01)$ (Table 1). Multiple organ dysfunction also occurred in higher frequency among transferred than non-transferred children $(32 \%$ vs. $24 \%$, $p<.01)$. There was no difference in the frequency of comorbidities by transfer status.

Transfer hospitalization was notably associated with higher use of invasive medical devices including arterial catheters, invasive mechanical ventilation, central venous catheters; and specialized technology, including CRRT and ECMO (Table 2). The occurrence of CPR did not differ by transfer status, occurring in $3.8 \%$ of transferred and $3.9 \%$ of non-transferred children $(p=0.84)$.

Unadjusted outcomes and resource use differed significantly between transferred and non-transferred children. Transferred children had longer hospitalization (30 vs. 22 days, $p<.05)$ and accrued higher hospital charges $(\$ 385,275$ vs. $\$ 290,882, \mathrm{p}<.05)$. Crude mortality was also higher among transferred than non-transferred children (21.4\% vs. $15.0 \%, p<.01)$.

After multivariate adjustment for potential confounders, adjusted in-hospital mortality was not statistically different between transferred and non-transferred 
Table 1 Distribution of patient and hospital characteristics according to transfer status

\begin{tabular}{|c|c|c|c|c|}
\hline Characteristic & $\begin{array}{l}\text { Overall Hospitalizations } \\
(n=8533) \%\end{array}$ & $\begin{array}{l}\text { Transfer Hospitalizations } \\
(n=2151) \%\end{array}$ & $\begin{array}{l}\text { Non-transfer Hospitalizations } \\
(n=6382) \%\end{array}$ & $p$ \\
\hline \multicolumn{5}{|l|}{ Age in Years } \\
\hline$<1$ & 29.1 & 39.6 & 25.5 & \\
\hline $1-5$ & 15.1 & 14.0 & 15.5 & \\
\hline $6-10$ & 9.0 & 8.1 & 9.2 & \\
\hline $11-15$ & 13.6 & 14.1 & 13.5 & \\
\hline $16-20$ & 33.2 & 24.2 & 36.3 & $<0.0001$ \\
\hline Female Sex & 48.9 & 47.3 & 49.5 & 0.07 \\
\hline \multicolumn{5}{|c|}{ APRDRG Levels of IIIness Severity } \\
\hline Minor/Moderate & 5.1 & 3.3 & 5.8 & \\
\hline Major & 17.8 & 12.5 & 19.7 & \\
\hline Extreme & 77.0 & 84.2 & 74.5 & $<0.0001$ \\
\hline \multicolumn{5}{|l|}{ Primary Payer } \\
\hline Public & 51.9 & 55.6 & 50.6 & \\
\hline Private & 37.4 & 33.5 & 38.8 & \\
\hline Self-pay/Other & 10.7 & 10.9 & 10.6 & 0.0015 \\
\hline \multicolumn{5}{|l|}{ Type of Hospital } \\
\hline Rural & 2.1 & 1.2 & 2.4 & \\
\hline Urban Non-Teaching & 12.7 & 4.6 & 15.4 & \\
\hline Urban Teaching & 85.2 & 94.2 & 82.2 & $<0.0001$ \\
\hline
\end{tabular}

children (Odds Ratio:1.04, 95\% Confidence interval $[\mathrm{CI}]: 0.88-1.24)$. Similarly, adjusted length of hospital stay (1.1 days; 95\% CI: - 1.2-3.4 days) and hospital charges $(-2814 ; 95 \%$ CI: $-31,656$ - 26,028) for transferred versus non-transferred children were not statistically different.

\section{Discussion}

One out of every four hospitalizations for children with severe sepsis or septic shock in the U.S. in 2012 was associated with interhospital transfer. While the exact indication for such transfer is unknown, the higher use of invasive medical devices and specialized medical technology such as ECMO and CRRT suggested these children were severely ill and in need of escalated care, likely prompting transfer.

Interhospital transfer is often indicative of a mismatch between a patient's needs and the locally-available resources $[14,15]$, with the hope of salutary outcomes if such transfer was performed in a timely manner. Death from pediatric sepsis is often associated with multiple organ dysfunction the progression of which could be halted or reversed by timely institution of organsupportive therapies [7, 16].

The study findings highlight significant variation in illness burden and resource-utilization by transfer status, with transfer hospitalizations more likely to involve

Table 2 Distribution of invasive medical technology according to transfer status

\begin{tabular}{|c|c|c|c|c|}
\hline Characteristic & $\begin{array}{l}\text { Overall Hospitalizations } \\
(n=8533) \%\end{array}$ & $\begin{array}{l}\text { Transfer Hospitalizations } \\
(n=2151) \%\end{array}$ & $\begin{array}{l}\text { Non-transfer Hospitalizations } \\
(n=6382) \%\end{array}$ & $p$ \\
\hline \multicolumn{5}{|l|}{ Invasive Medical Technology } \\
\hline Mechanical ventilation & 51.4 & 65.4 & 46.6 & $<0.0001$ \\
\hline Arterial catheterization & 23.1 & 27.0 & 21.8 & $<0.0001$ \\
\hline Central venous catheterization & 37.4 & 40.9 & 36.2 & 0.0006 \\
\hline Tracheostomy & 3.8 & 5.5 & 3.3 & $<0.0001$ \\
\hline ECMO & 2.8 & 5.7 & 1.8 & $<0.0001$ \\
\hline CRRT & 5.0 & 6.2 & 4.6 & 0.0072 \\
\hline
\end{tabular}


children with extreme illness severity who were most often admitted to urban teaching hospitals. It was therefore not surprising that children who were transferred were more likely to undergo invasive medical device placement including arterial and central venous catheterization, tracheostomy, and invasive mechanical ventilation. This observation corroborates prior findings of higher resource utilization among critically ill patients who underwent inter-hospital transfer compared to those who did not [17]. Highly specialized and expensive technologies, including ECMO and CRRT, were similarly more likely to be deployed in the care of transferred children in comparison with non-transferred children. This finding of higher frequency of use of specialized technology among transferred versus non-transferred children, is likely indicative of greater illness severity among transferred children, corroborating prior report of an association between illness severity and deployment of invasive medical devices among the critically ill pediatric population [18]. The use of these technologies might have mitigated the impact of multiple organ dysfunction on patient death by limiting progression of organ dysfunction or enhancing resolution of organ dysfunction. Such assertion is supported by the observation that despite higher unadjusted mortality among transfer versus non-transfer hospitalizations, the mortality difference was no longer observed after multivariate adjustment for potential confounders including illness severity. This finding of similar severityadjusted mortality also indicates the need to investigate processes of care and quality of care factors within the receiving urban hospitals that contributed to reduction in observed mortality.

Receiving hospitals bore a significant resource use burden reflected in their greater use of invasive medical technology along with the longer hospitalization and higher charges among transferred children in comparison to the non-transferred children. This disparate resource use burden was no longer evident after multivariate adjustment for potential factors that could confound the relationship between transfer status and resource use. The findings have implications for urban teaching hospitals that bear the brunt of these transfer hospitalizations. The first implication stems from the observation that higher charges and longer hospitalization among the transfer hospitalizations appeared commensurate to the severity of patient illness. Efforts to benchmark outcomes and resource use between hospitals that take care of critically ill children need to incorporate transfer admissions into algorithms for such inter-institutional assessments to avoid penalizing the receiving hospitals, as previously advocated for critically ill adults
$[19,20]$. Secondly, as an extension of this prior concept, the study findings highlight the need to routinely adjust in-hospital outcomes and resource use for illness severity and case mix [21, 22], without which hospitals that receive critically ill patients on interhospital transfer might be penalized for higher crude mortality and greater resource use.

The primary payer is an important variable that serves as a proxy for socioeconomic status. Public insurance coverage was associated with transfer status, a finding that corroborates recent work that noted significant variation in patient care processes, including transfer, by patients' insurance coverage [23]. Given that such variation might impact patient outcomes [24], further work is warranted to investigate the reasons for such variation and the potential impact on outcomes and resource use in children with severe sepsis or septic shock.

The findings of the current study should be interpreted in light of certain limitations. It is vital to note that the reported hospital charges and LOS in the current study accrued from the care received at the hospital of definitive care thereby discounting the resource use expended at the referring hospital prior to interhospital transfer. As a result, the reported resource use burden accrued by the transferred children is likely an under-estimate of the actual burden. This limitation, imposed by the absence of linkable data for transferred children across hospitals in the data source for the study, highlights the need to conduct future longitudinal studies to provide a complete picture of the overall resource burden borne by children with pediatric sepsis who undergo transfer hospitalizations.

The KID is a database of administrative discharge data without clinical information beyond what can be captured in ICD-9-CM diagnosis and procedure codes. Therefore, it was not possible to study the clinical course for each patient, the need for and receipt of various therapeutic interventions, and how clinical care was coordinated at the patient and hospital level. An additional limitation is that the identification of cases of severe sepsis was ascertained via ICD-9-CM diagnosis codes, and is susceptible to inaccuracies of detection and attribution that may have biased our findings.

Also, while the care of patients with severe sepsis or septic shock might be improved by early resuscitation in the community prior to transfer to referral hospitals [7], determination of the characteristics of the referring hospitals and the circumstances surrounding transfer among the transfer hospitalizations, was not possible in the current study. This limited the ability to investigate any delay in resuscitative 
care, which might impact clinical outcomes and resource-utilization at the receiving hospital. Given the lack of clinical data, the characteristics and process of inter-hospital transport, and their potential impact on patient-level resource use and outcomes could not be ascertained. The KID contains nonclinical administrative data collected during patient hospitalizations and has no follow-up or longitudinal information on patients after hospital discharge. This limitation did not permit determination of long term patient morbidity and functional status.

\section{Conclusion}

One in four children with severe sepsis or septic shock required interhospital transfer for specialized care associated with greater use of invasive medical devices and specialized technology. Despite higher crude mortality and resource consumption among transferred children, adjusted mortality and resource use did not differ by transfer status. Further research should identify quality-of-care factors at the receiving hospitals that influenced clinical outcomes and resource use for critically ill children with severe sepsis or septic shock.

\section{Appendix A}

\section{List of comorbidities [11]}

Cardiovascular: Heart and great vessel malformations, cardiomyopathies, conduction disorders and dysrhythmias.

Respiratory: Respiratory malformations, chronic respiratory disease, and cystic fibrosis.

Renal and Urologic: Congenital anomalies, and chronic renal failure.

Neurologic and Neuromuscular: Brain and spinal cord malformations, mental retardation, central nervous system degeneration and disease, infantile cerebral palsy, epilepsy, muscular dystrophies and myopathies.

Gastrointestinal: Congenital anomalies, chronic liver disease and cirrhosis, inflammatory bowel disease.

Hematologic or immunologic: Sickle cell disease, hereditary anemias, hereditary immunodeficiency, human immunodeficiency virus disease.

Metabolic: Amino acid metabolism, carbohydrate metabolism, lipid metabolism, storage disorders; other metabolic disorders.

Other congenital or genetic defect: Chromosomal anomalies, bone and joint anomalies, diaphragm and abdominal wall, other congenital anomalies.

Malignancy

Neonatal

Technology dependency

Transplantation

\section{Appendix B}

Table 3 Diagnosis codes used to identify organ dysfunction [12]

\begin{tabular}{|c|c|c|}
\hline $\begin{array}{l}\text { Organ } \\
\text { Dysfunction }\end{array}$ & $\begin{array}{l}\text { ICD-9-CM } \\
\text { codes }\end{array}$ & Diagnosis \\
\hline \multirow[t]{6}{*}{ Respiratory } & 518.81 & Acute respiratory failure \\
\hline & 518.82 & Acute respiratory distress, insufficiency \\
\hline & 518.5 & $\begin{array}{l}\text { Pulmonary insufficiency following trauma } \\
\text { and surgery }\end{array}$ \\
\hline & 799.1 & $\begin{array}{l}\text { Respiratory arrest, cardiorespiratory } \\
\text { failure }\end{array}$ \\
\hline & 96.7 & Mechanical ventilation \\
\hline & 518.84 & Acute-on-chronic respiratory failure \\
\hline \multirow[t]{4}{*}{ Cardiovascular } & 785.50 & $\begin{array}{l}\text { Shock unspecified, failure of peripheral } \\
\text { circulation }\end{array}$ \\
\hline & 785.59 & Other shock, Septic \\
\hline & 458 & Hypotension \\
\hline & 427.5 & Cardiac arrest \\
\hline \multirow[t]{5}{*}{ Neurologic } & 293 & Transient organic psychosis \\
\hline & 348.1 & Anoxic brain injury \\
\hline & 348.3 & Acute encephalopathy \\
\hline & 780.01 & Coma \\
\hline & 780.09 & Altered consciousness, unspecified \\
\hline \multirow[t]{2}{*}{ Hepatic } & 570 & Acute and subacute necrosis of liver \\
\hline & 573.4 & Hepatic infarction \\
\hline \multirow[t]{4}{*}{ Hematologic } & 286.6 & $\begin{array}{l}\text { Defibrination syndrome, disseminated } \\
\text { intravascular coagulation }\end{array}$ \\
\hline & 286.9 & $\begin{array}{l}\text { Other and unspecified coagulation } \\
\text { defects }\end{array}$ \\
\hline & 287.4 & Secondary thrombocytopenia \\
\hline & 287.5 & Thrombocytopenia, unspecified \\
\hline \multirow[t]{3}{*}{ Renal } & 584 & Acute renal failure \\
\hline & 586 & Renal failure, unspecified \\
\hline & 788.5 & Oliguria, anuria \\
\hline
\end{tabular}

Abbreviations

APRDRG: All-patient refined diagnostic related group; KID: Kids' Inpatient Database; LOS: Length of stay

\section{Acknowledgements}

Not applicable.

\section{Authors' contributions}

FOO participated in study conception and design, data acquisition and interpretation, drafting of the manuscript, and critical revision of the manuscript for important intellectual content. AG participated in data analysis and interpretation, drafting of the manuscript, and critical revision of the manuscript for important intellectual content. Both authors have read and approved the manuscript.
Funding

None. 


\section{Availability of data and materials}

The KID is a publicly available dataset. The datasets used and analyzed during the current study are available from the corresponding author on reasonable request.

\section{Ethics approval and consent to participate}

The Institutional Review Board of the University of Michigan Medical Schoo approved the study.

\section{Consent for publication}

Not applicable.

\section{Competing interests}

The authors declare that they have no competing interests.

Received: 1 November 2018 Accepted: 6 June 2019

Published online: 13 June 2019

\section{References}

1. Watson RS, Carcillo JA, Linde-Zwirble WT, Clermont G, Lidicker J, Angus DC. The epidemiology of severe sepsis in children in the United States. Am J Respir Crit Care Med. 2003:167:695-701.

2. Weiss SL, Fitzgerald JC, Pappachan J, Wheeler D, Jaramillo-Bustamante JC, Salloo A, et al. Sepsis prevalence, outcomes, and therapies (SPROUT) study investigators and pediatric acute lung injury and Sepsis investigators (PALISI) network. Global epidemiology of pediatric severe sepsis: the sepsis prevalence, outcomes, and therapies study. Am J Respir Crit Care Med. 2015;191:1147-57.

3. Hartman ME, Linde-Zwirble WT, Angus DC, Watson RS. Trends in the epidemiology of pediatric severe sepsis. Pediatr Crit Care Med. 2013;14:686-93.

4. Leclerc F, Leteurtre S, Duhamel A, Grandbastien B, Proulx F, Martinot A, Gauvin F, Hubert P, Lacroix J. Cumulative influence of organ dysfunctions and septic state on mortality of critically ill children. Am J Respir Crit Care Med. 2005;171:348-53.

5. Odetola FO, Shanley TP, Gurney JG, Clark SJ, Dechert RE, Freed GL, et al. Characteristics and outcomes of interhospital transfers from level II to level I pediatric intensive care units. Pediatr Crit Care Med. 2006:7:536-40.

6. Odetola FO, Gebremariam A, Freed GL. Patient and hospital correlates of clinical outcomes and resource utilization in severe pediatric sepsis. Pediatrics. 2007;119:487-94

7. Han YY, Carcillo JA, Dragotta MA, Bills DM, Watson RS, Westerman ME, Orr RA. Early reversal of pediatric-neonatal septic shock by community physicians is associated with improved outcome. Pediatrics. 2003;112:793-9.

8. Weiss SL, Fitzgerald JC, Balamuth F, Alpern ER, Lavelle J, Chilutti M, Grundmeier R, Nadkarni VM, Thomas NJ. Delayed antimicrobial therapy increases mortality and organ dysfunction duration in pediatric sepsis. Crit Care Med. 2014;42:2409-17.

9. Odetola F, Gebremariam A. Transfer hospitalizations for pediatric severe Sepsis and septic shock: resource use and outcomes. Crit Care Med. 2018; 46:747 suppl.

10. HCUP Kids' Inpatient Database (KID). Healthcare Cost and Utilization Project (HCUP). Rockville, MD: Agency for Healthcare Research and Quality; 2012. www.hcup-us.ahrq.gov/kidoverview.jsp

11. Feudtner C, Feinstein JA, Zhong W, Hall M, Dai D. Pediatric complex chronic conditions classification system version 2: updated for ICD-10 and complex medical technology dependence and transplantation. BMC Pediatr. 2014;14:199.

12. Johnston JA, Yi MS, Britto MT, Mrus JM. Importance of organ dysfunction in determining hospital outcomes in children. J Pediatr. 2004;144(5):595-601.

13. Odetola FO, Davis MM, Cohn LM, Clark SJ. Interhospital transfer of critically ill and injured children: an evaluation of transfer patterns, resource utilization, and clinical outcomes. J Hosp Med. 2009;4:164-70.

14. Odetola FO, Clark SJ, Gurney JG, Donohue JE, Gebremariam A, DuBois L, et al. Factors associated with interhospital transfer of children with respiratory failure from level II to level I pediatric intensive care units. J Crit Care. 2015;30:1080-4.

15. Odetola FO, Anspach RR, Han YY, Clark SJ. Interhospital transfer of children in respiratory failure: a clinician interview qualitative study. J Crit Care. 2017; 37:162-72.

16. Carcillo JA, Davis AL, Zaritsky A. Role of early fluid resuscitation in pediatric septic shock. JAMA. 1991;266:1242-5.
17. Odetola FO, Clark SJ, Gurney JG, Dechert RE, Shanley TP, Freed GL. Effect of interhospital transfer on resource utilization and outcomes at a tertiary pediatric intensive care unit. J Crit Care. 2009;24:379-86.

18. Yeh TS, Pollack MM, Holbrook PR, Fields Al, Ruttiman U. Assessment of pediatric intensive care - application of the therapeutic intervention scoring system. Crit Care Med. 1982;10:497-500.

19. Rosenberg AL, Hofer TP, Strachan C, Watts CM, Hayward RA. Accepting critically ill transfer patients: adverse effect on a referral center's outcome and benchmark measures. Ann Intern Med. 2003;138:882-90.

20. Borlase BC, Baxter JK, Kenney PR, Forse RA, Benotti PN, Blackburn GL. Elective intrahospital admissions versus acute interhospital transfers to a surgical intensive care unit: cost and outcome prediction. J Trauma. 1991;31:915-8.

21. Wagner DP, Knaus WA, Draper EA. The case for adjusting hospital death rates for severity of illness. Health Aff (Millwood). 1986;5:148-53.

22. Pollack MM, Ruttimann UE, Getson PR. Accurate prediction of the outcome of pediatric intensive care: a new quantitative method. N Engl J Med. 1987; 316:134-9.

23. Venkatesh AK, Chou SC, Li SX, Choi J, Ross JS, D'Onofrio G, et al. Association between insurance status and access to Hospital Care in Emergency Department Disposition. JAMA Intern Med. 2019. https://doi.org/10.1001/ jamainternmed.2019.0037 Epub ahead of print.

24. Kim TH, Ro YS, Shin SD, Song KJ, Hong KJ, Park JH, et al. Association of health insurance with post-resuscitation care and neurological outcomes after return of spontaneous circulation in out-of-hospital cardiac arrest patients in Korea. Resuscitation. 2019;135:176-82.

\section{Publisher's Note}

Springer Nature remains neutral with regard to jurisdictional claims in published maps and institutional affiliations.
Ready to submit your research? Choose BMC and benefit from:

- fast, convenient online submission

- thorough peer review by experienced researchers in your field

- rapid publication on acceptance

- support for research data, including large and complex data types

- gold Open Access which fosters wider collaboration and increased citations

- maximum visibility for your research: over $100 \mathrm{M}$ website views per year

At BMC, research is always in progress.

Learn more biomedcentral.com/submissions 